\title{
EDÉN PATAGÓNICO, UNA LECTURA DEL ESPACIO EN LA ESPADA ENCENDIDA ${ }^{1}$
}

\author{
Brenda Müller \\ Universidad de Chile \\ leontinamullerh@hotmail.com
}

RESUMEN / ABSTRACT

En esta lectura de La espada encendida, se prestará atención al espacio que se configura como ámbito edénico al interior del mundo representado en la fábula. Espacio que tiene como referente al vasto territorio de la Patagonia chilena y como intertexto el jardín edénico del mito bíblico de Adán y Eva. Pero más que centrarse en el espacio representado, interesa indagar en el sentido que la imagen de la Patagonia tiene al interior del universo poético nerudiano, sentido que explicaría, en alguna medida, la elección de este nuevo Edén salvaje y solitario por parte del sujeto poético, como lugar primordial desde donde volver a pensar una nueva vida histórica distante del paradigma cristiano de fundación de mundo.

Palabras-Clave: sur, Patagonia, Edén, deshabitado, no consagrado.

When reading La espada encendida, attention focuses on the grandeur of the inner world described in the fable. The physical territory is none other than the vast Chilean Patagonia, which is related to the biblical Garden of Adam and Eve. Instead of concentrating on the physical space, emphasis is given to the poetic sense that Neruda attempted to give to this region. In doing so, we could better explain why the poet chose this remote and wild area, perhaps as a starting point to formulate a new world development that deviates from the Christian paradigm of the world's foundation.

KEY WORDS: South, Chilean Patagonia, Eden, uninhabited and non-consecrated space.

1 Este trabajo corresponde a un capítulo de la tesis "Mujer y geografía en La espada encendida". 
El poemario de La espada encendida ${ }^{2}$ publicado en 1970, pertenece a la última etapa escritural de Pablo Neruda y la crítica lo ha interpretado como una propuesta ficticio-mítica de refundación histórica a través del vínculo erótico de una pareja primordial.

Interesa en esta lectura focalizar la atención en el espacio que se configura como ámbito edénico al interior del mundo representado en la fábula. Este lugar, aunque mítico, no tiene un referente fantástico o indeterminado, sino que uno bien preciso que corresponde a la vasta zona patagónica chilena representada como lugar edénico apelando al mito bíblico de Adán y Eva, intertexto que es sometido a un intenso cuestionamiento al interior del mundo plasmado en la fábula. Cabe hacer notar que en una lectura actual de este corpus poemático, llama inmediatamente la atención el referente geográfico apelado en el texto, más aún si se considera que hoy en día la Patagonia tiene plena vigencia y vital importancia en el contexto de la preocupación ambiental a escala global. Claro que no siempre fue así. La historia y la literatura referida a esta zona del extremo austral de Sudamérica remiten a una imagen de la Patagonia que no tiene mucho que ver con la relevancia ecológica que hoy se le asigna. En este sentido, su ubicación remota, su clima y fisiografía compleja fueron rasgos que cimentaron en el imaginario universal la representación de la Patagonia como Terra incógnita y Finis Terrae. Esta imagen implicaba características más bien negativas del paisaje patagónico: lugar ubicado más allá de todo lo conocido, por lo tanto, espacio salvaje y amenazante para el ser humano. Sin embargo, en la actualidad y paradójicamente, esta condición marginal de la zona debido a sus rasgos peculiares es lo que permite que esta región del extremo austral chileno sea apreciada como uno de los últimos lugares prístinos que quedan en el planeta. Esta revaloración del espacio patagónico, en su calidad de naturaleza intocada, está presente también en el habitante europeo actual, quien parece estar ansioso por contemplar espacios naturales aún no vulnerados por la civilización, tal vez ya harto de observar aquellas bellísimas obras construidas por el hombre. Por eso es que vuelve ahora en pequeñas oleadas turísticas a visitar estos territorios australes, ya no como expedicionarios o conquistadores, es de esperar, sino a descubrir, quizás,

2 Todos los textos de Pablo Neruda citados en este trabajo corresponden a la edición completa de sus obras en cinco volúmenes, a cargo de Hernán Loyola. En lo sucesivo se abreviará como sigue: $O C$, Vol. pp. con excepción del texto analizado, La espada encendida, al cual se hará referencia mediante indicación del fragmento en números romanos. 
alguna catedral nerudiana, de esas que nacen de debajo de la tierra como raíces monumentales volcadas hacia arriba, como la propia palabra del sujeto poético nacida también de esta tierra ubicada "en el fondo de América sin nombre" ( OC I, 432).

Volviendo al poemario y al mundo representado en la fábula, este Edén patagónico en abierto y fructífero diálogo con su intertexto bíblico, es concebido como el "nuevo Edén salvaje y solitario" (OC III, 547) hasta donde Rhodo, el personaje protagonista llega a instalarse, después de huir de un mundo devastado. Entonces cabe preguntarse, ¿por qué este "paraíso de agua y soledad" (XVII) y no un locus amoenus semejante al descrito en el Génesis? O planteado de otro modo, ¿qué tiene de edénico este espacio indómito? Para intentar una respuesta habrá que atender primero al referente geográfico de este ámbito primigenio, considerando sus rasgos peculiares, luego también será necesario indagar acerca de la existencia de lo deshabitado al interior del universo nerudiano como espacio concreto, cuyo referente tiene una ubicación geográfica austral plenamente identificable en el territorio chileno. Finalmente, se examinará la condición de este espacio como lugar no consagrado, vale decir, como ámbito primordial ajeno a la historia de violencia y muerte que constituye el pasado del protagonista en el mundo de la fábula. Experiencia del sujeto que se sustenta, en última instancia, en el paradigma histórico-cristiano de fundación de mundo.

\section{LA SINGULARIDAD DEL REFERENTE AUSTRAL, EL JARDÍN ORIGINAL}

En una primera lectura, la condición de fábula mítica ${ }^{3}$ de este texto pudiera hacer pensar, y con justa razón, que el espacio configurado obedece a un escenario fantástico, telón de fondo que poco o nada tendría que ver con un referente concreto, pero tal situación no es así en absoluto. Lo que hace

3 La fábula en su definición como género literario, además de su carácter ejemplarizador, porta como uno de sus principales rasgos, la narración de hechos imaginarios y maravillosos pertenecientes al campo de lo alegórico. De este modo los elementos del mundo configurado generalmente escapan a referentes reconocibles en el plano de lo real, como acontece, por ejemplo, con algunos de los animales que habitan este Edén patagónico, los que aparecen descritos con nombres y rasgos fantásticos: Saurios, tribelias, polytálamos, etc. (véase fragmento LII). Con el espacio, sin embargo, no ocurre lo mismo como se intenta mostrar en esta lectura. 
Neruda es circunscribir un lugar físico plenamente identificable en el extratexto para reelaborarlo como espacio ficticio-mítico: "Era el cerco glacial de la naturaleza:/ de Aysén al Sur la Patagonia infligió/las desoladas cláusulas del invierno terrestre" (II). El lugar descrito corresponde a una zona geográfica bastante determinada y localizable en el extremo sur de Chile, la cual presenta rasgos muy peculiares en lo que a su fisiografía y condiciones climáticas se refiere, tal y como aparece representada en la mayor parte del poemario. La intrincada geografía y la rigurosidad del clima son características que definen la zona patagónica, como se describe en el fragmento IV:

(En el extremo de Chile se rompe el planeta:

el mar y el fuego, la ciencia de las olas,

los golpes del volcán, el martillo del viento,

la racha dura con su filo furioso,

cortaron tierras y aguas, las separaron: crecieron

islas de fósforo, estrellas verdes, canales invitados,

selvas como racimos, roncos desfiladeros:

en aquel mundo de fragancia fría

Rhodo fundó su reino.)

La zona que se conoce como la Patagonia chilena es una vasta extensión que geopolíticamente se divide en dos sectores: Patagonia Norte, que comprende desde la provincia de Palena, ubicada en la X Región de Los Lagos, hasta la XI Región de Aysén. El otro sector corresponde a la Patagonia Sur, que abarca la XII Región de Magallanes hasta la Antártica chilena. Todo este inmenso territorio despliega una gran variedad de paisajes, desde las pampas patagónicas, al oriente, a los fiordos, canales e islas al poniente, generados éstos por el surgimiento parcial de la Cordillera de los Andes en el Océano Pacífico austral. Numerosos ríos, lagos y glaciares, cercados por la altura de ventisqueros y volcanes, forman parte también del paisaje patagónico, como asimismo los dos extensos campos de hielo norte y sur, la mayor reserva de agua dulce del planeta.

La lluvia y el viento son rasgos emblemáticos que identifican gran parte de esta región. La pluviometría supera en promedio los $2000 \mathrm{~mm}$ anuales, lo que hace a esta zona una de las más lluviosas del mundo. El clima difícil sumado a una fisiografía laberíntica ha permitido el desarrollo de una flora y fauna propias del lugar, poseyendo muchas de sus especies carácter endémico. La pluviselva fría austral es también reflejo de estas singulares condiciones ambientales. 
La crudeza climática y la escabrosa geografía han sido factor determinantes en el escaso poblamiento de la mayor parte de la región. Estas condiciones adversas han impedido que la vida humana haya tenido éxito como acción dominadora de la naturaleza, permitiendo, de este modo, la conservación de gran parte del paisaje en su estado original. El Archipiélago Patagónico es de esos pocos lugares marginales que quedan en el mundo a los cuales Mateo Martinic, académico y estudioso de la región, denomina "relictos de pristinidad" (258), destacando el carácter de excepcionalidad que estos espacios presentan al compararlos con la mayor parte del territorio habitado del planeta. Así lo enfatiza al referirse al sector que describe: "No muestra el Archipiélago Patagónico, y jamás podrá hacerlo, los rasgos humanizados en su paisaje, propios de una acción antrópica permanente y modificadora de la naturaleza" (258).

Una primera respuesta a la pregunta por la condición de correlato edénico del espacio representado puede darse atendiendo a la calidad de paisaje prístino que tiene el referente patagónico. Ciertamente, sus rasgos remiten a un escenario primordial, vestigio de un espacio arcaico donde el hombre aún no imponía su presencia, sino que era uno más en un mundo recién creado, donde estaba todo por hacerse. El paisaje patagónico, por sus atributos peculiares, rememora ese período mítico de iniciación de la vida en la Tierra, cuando la historia humana todavía no comenzaba. De este modo se representa en el mundo de la fábula, como ámbito intocado, ajeno a la vida histórica, territorio primigenio, lejano y solitario:

\author{
[...] y como este hombre no tenía cielo \\ buscó la enmarañada rosa verde \\ del territorio secreto: \\ nadie allí había matado una paloma, \\ ni una abeja, ni un nardo, \\ los zorros color de humo bebían con los pájaros \\ bajo la magnitud virgen del avellano [...] (XVI).
}

\title{
2. EDÉN PATAGÓNICO, LA EXISTENCIA DE LO DESHABITADO
}

La pristinidad será entonces el primer elemento en el cual se funda la calidad edénica del espacio patagónico. Al igual que su correlato bíblico, se está en presencia de un lugar primordial e inhabitado en el que la experiencia histórica 
no tiene existencia. Vale decir no hay en este espacio quehacer humano entendido como lo que se conoce de modo general por civilización. Pero a diferencia del espacio edénico del Génesis, éste no es un jardín delicioso, sino un ámbito donde la naturaleza se impone de manera absoluta.

Alain Sicard se refiere a la especial relación del enunciador nerudiano con la naturaleza, relación que describe como un proceso de identificación del sujeto con su origen material y que el autor resume en la ficción de la deshabitación (359-382). Para Sicard, esta noción de lo deshabitado funciona solo en la dialéctica naturaleza/ historia, donde, no obstante, la dependencia recíproca de ambos elementos para su vigencia, la experiencia material de lo deshabitado estará siempre subordinada a la experiencia histórica del sujeto. En otras palabras, lo que propone Sicard es que en el universo nerudiano lo deshabitado cobra existencia solo si hay historia. Sin embargo, la afirmación anterior desdibuja o difumina aquella naturaleza austral específica hacia la cual el sujeto dirigió su mirada y su palabra como fundamento mítico identitario en el despliegue de su mundo poético.

Interesa detenerse en esta noción de lo deshabitado que este autor propone, puesto que en su análisis de La espada encendida aplica este mismo criterio dialéctico, anulando o invisibilizando la representación del espacio patagónico.

Sicard asimila la noción de lo deshabitado con la experiencia de inmersión en la materia o ficción del extravio por parte del sujeto poético. Este extravío acontece en la espesura inhabitada: "En la espesura, la consciencia experimenta su propio desvanecimiento dentro del mundo material" (368). Esta pérdida de sí en el abismo vegetal, como también la denomina, será inaugurada por esa primera desorientación infantil en los bosques sureños, ritual de comunión con lo deshabitado, comenzado en la infancia del sujeto y que aparece descrito en el poema "La tierra austral", de Memorial de Isla Negra, ceremonia que se seguirá celebrando a lo largo de toda la trayectoria poética del enunciador nerudiano. La experiencia de lo deshabitado se nutre de la ficción de inmersión en lo material, asociada a la vivencia infantil del extravío en el bosque, donde este extravío adquiere connotaciones simbólicas que explicarían desde temprano en la vida del sujeto poético la dialéctica naturaleza/historia, según lo propuesto por Sicard. Esta pérdida en lo deshabitado solo tendría un carácter ficticio, puesto que la inmersión o fusión con la naturaleza implica desaparecer como sujeto, vale decir, volverse materia también, vivencia ciertamente imposible desde que se tiene conciencia. Es posible advertir que la noción de lo deshabitado postulada por Sicard no da cabida a la existencia concreta 
de un espacio natural no habitado, toda vez que el acceso a lo deshabitado implica desaparecer como conciencia. De este modo, el paisaje patagónico, representado como espacio edénico en la fábula, se desrealiza, perdiendo consistencia, quedando relegado al ámbito de la ficción al interior de la dialéctica naturaleza/historia que Sicard propone:

No obstante, para Neruda, lo deshabitado, en tanto tal, no existe. Este será el gran mensaje de La espada encendida: Ningún Edén, ninguna soledad escapan a la historia. Lo deshabitado no es más que la ficción que se inventa la consciencia para imaginarse material: no hay existencia fuera de la contradicción que la opone y la une a lo que no es ella misma (381).

No cabe duda de que lo deshabitado entreverado con la ficción del extravio no tiene más que una existencia contradictoria, no puede ser de otro modo, nada existe fuera del breve tramo que cubre la vida humana. Conciencia e historia resultan ser modos de denominar la trayectoria vivida. Pero lo deshabitado no puede asimilarse a la ficción del extravio, es preciso separar ambas nociones al interior del universo nerudiano. El extravío como inmersión en la materialidad se ajusta a esta dinámica de naturaleza e historia propuesta por Sicard. No así lo deshabitado, que en su acepción más común lleva implícito el espacio concreto, la definición clara y simple de lugar no habitado, por lo tanto, interpretarlo como ámbito inexistente en relación con la historia resta validez y neutraliza las imágenes que tienen como referente el espacio austral en el imaginario poético de Neruda. Más que detenerse en el lugar concreto representado, éste se asimila inmediatamente a una espesura general y arquetípica, de acuerdo a la interpretación de Sicard, como ocurre con la interpretación del espacio patagónico en el mundo representado en la fábula. La definición que este autor propone de espesura no hace más que corroborar lo recién expuesto:

"La espesura" sería una naturaleza sin el hombre, el reino de lo deshabitado. Habremos de matizar esta definición. Pero "la espesura" será, de todos modos, ese paisaje como anterior a la historia humana cuyo arquetipo proyectará el poeta sobre otros paisajes conocidos a lo largo de sus viajes a Java y a Ceylán, en los bosques de Polonia, e incluso en México (366).

Sin embargo, a partir de los mismos poemas citados en nota por Sicard, es posible advertir cuánta importancia le da el sujeto poético al espacio específico 
del sur chileno, a esa espesura austral que nada tiene que ver con los otros espacios aludidos, no al menos con Java y Polonia. En relación con los viajes a Java y a Ceylán que refieren al poema "El deshabitado", de Residencia en la tierra, se puede afirmar que el paisaje de Java aparece en ese texto como lugar repudiado y en abierto contraste frente a ese Sur mítico que luego emerge con gran vigor en el poema:

Lo demás, hasta muy larga distancia permanece inmóvil, cubierto por el mes de junio y sus vegetaciones mojadas, sus animales callados, se unen como olas. Sí, que mar de invierno, qué dominio sumergido trata de sobrevivir, $\mathrm{y}$, aparentemente muerto, cruza de largos velámenes mortuorios esta densa superficie? (OC, I, 281-282)

Se advierte cómo desde la expresión "lo demás" se alude a esa espesura chilena, que es la que se describe a continuación, esa tierra y ese mar austral que se precipita en la memoria recorriendo inmensas distancias para instalarse en la nostalgia del sujeto, reminiscencia que parece sostenerlo en ese extraño y ajeno territorio en el que en ese momento se encuentra ${ }^{4}$. Los bosques de Polonia, por otro lado, referidos en el poema "Canta Polonia", del texto Las uvas y el viento, no alcanzan el estatuto de espesura en el sentido de espacio material de origen del sujeto. Estos bosques tienen un rol secundario en el texto, débil si se quiere, actuando más bien de telón de fondo para alabar una experiencia histórica victoriosa.

En definitiva, la ficción del extravío, aunque implica un intento de fusión con la materialidad que anida en lo deshabitado, no puede confundirse con el espacio no habitado que tiene siempre un referente en el universo nerudiano. La ficción del extravio es deseo, aspiración, desvarío, ensoñación. Lo deshabitado, en cambio, es un lugar concreto que tiene realidad y consistencia, ocupando un espacio determinado y será siempre en el itinerario del sujeto poético una región mítica cuyo referente posee una ubicación austral. Será la zona de la Frontera o Región de la Araucanía, situada en el territorio austral chileno. Será también aquella "América sin nombre" situada al sur del mundo y Chile mismo ubicado al sur de América del Sur. Finalmente será, la Patagonia, esa Terra incógnita que se pierde en el Polo Sur.

4 Neruda habría escrito este poema en Batavia (Java). Así lo señala Hernán Loyola en la edición anotada y a su cargo de Residencia en la tierra. 
Jaime Concha señala la relevancia del territorio austral en el imaginario mítico nerudiano, como espacio que se rebela o que no se deja seducir por la historia:

Del Bío-Bío al Estrecho de Magallanes se funda el verdadero domicilio del poeta, congruente casi con la primitiva fisonomía de la tierra. La patria antes de toda posibilidad de historia, Chile antes de Chile. En efecto, el Estrecho de Magallanes imanta el espíritu del poeta hacia el sur. Más tarde, cuando regrese del Asia y navegue realmente por esas aguas finales del globo, este sur constituirá los pies físicos del territorio, su raíz extrema. El país se erguirá, entonces, a la mirada ansiosa del poeta que vuelve del exilio y de la separación, justamente desde esa latitud polar (62).

A la luz de lo que se ha venido planteando, lo deshabitado en esta fábula, entendido como espesura no habitada, ocupa un territorio bastante determinado: el espacio patagónico chileno, con todas las implicancias axiológicas que este ámbito austral tiene en la identidad del sujeto nerudiano. Espacio sin historia, entonces, no porque no hay conciencia, y por lo tanto lugar inexistente, sino porque la naturaleza indómita de la región ha impedido la intromisión del hombre y su acción modificadora. El dominio prácticamente absoluto de la naturaleza en gran parte de esta zona alejada del resto del territorio chileno habitado, revestirá al paisaje patagónico de un aura solemne y mágica, "fundada en su fuerza telúrica que parece emanar de todas partes, perceptible aún para el observador menos sensible" (Martinic 29). Fuerza telúrica que se dejará sentir como misterio que fascina, pero que también produce pavor. Fascinación y temor que Martinic explica, a partir de los rasgos singulares que la realidad de este espacio posee:

Ocurre que la misma [realidad] es proteiforme y por tanto puede exhibir con riqueza calidoscópica lo bello y lo sombrío, lo grandioso y lo pequeño, lo siniestro y lo que alegra, lo sublime y lo insignificante, la plenitud de la vida y el silencio pavoroso de la nada; todo ello es real, en increíbles matices (33).

En el mundo de la fábula se advierte también esta majestad de la naturaleza que irradia belleza, pero que a la vez se impone amenazante:

La bandurria salpica con canto de cuchara la dulzura fluvial de estas oceanías, 
el ave carpintera reparte en los raulíes una correspondencia con gotas de rocío, el puma abre los ojos y desarrolla el miedo: todo vive en la selva fría que se parece a la muerte: dentro de cada sombra crece un vuelo, las garras viven entre las raíces (VII).

Benjamín Subercaseaux, en la descripción que hace del espacio patagónico, después de visitar parte de la región en 1939, da cuenta, en alguna medida, de lo que evoca y representa este territorio en la mirada del hombre foráneo de la primera mitad del siglo XX:

Nunca en parte alguna, la geografía aparece como un esfuerzo más noble para fijar en una simple carta este mundo de inmensidad que arrolla a la creatura y la confunde con los accidentes del suelo. No hay vestigio en estas regiones de esa nota humana que hace del paisaje una materia plástica puesta al servicio de la vida. La naturaleza parece no saber nada del hombre ni importarle. No hay una choza, ni una huella del hacha en el árbol, ni un pilote que recuerde a un antiguo embarcadero. El hombre civilizado, frente a esta naturaleza, parece un extranjero, un intruso. Ella la inmensa, lo ocupa todo, lo acalla todo (Cit. en Martinic 29).

Otro testimonio más reciente, pero que no difiere sustancialmente de la descripción anterior, es el que ofrece Jacques Sautereau, explorador y espeleólogo francés, quien se adentró en el Archipiélago patagónico a comienzos del año 2000:

Todo es desmesurado: la amplitud de los macizos de mármol, la cantidad y el tamaño de las simas, grietas y acanaladuras, la violencia del viento y las precipitaciones [...] sin contar la falta total de presencia humana y las dificultades de aproximación: ausencia de caminos, rocas afiladas, relieves angustiosos, parcialmente recubiertos de una vegetación primaria, donde hay que progresar con brújula (2).

En resumen, el Edén patagónico, ámbito de lo deshabitado, se configura como lugar donde el dominio de la naturaleza es predominante, espacio en el cual han sido las propias características rigurosas de este ambiente prístino las que han impedido al sujeto histórico estar presente como agente que con su actuar y en su provecho modifica el ámbito natural de manera significativa. 
Sujeto histórico que como tal, solo se hará evidente al interior del universo nerudiano, a partir del proceso de ocupación conocido como "descubrimiento y conquista de América".

\section{UN ESPACIO NO CONSAGRADO, EL JARDÍN MÁS ÁSPERO Y SALVAJE}

Esta presencia avasalladora de la naturaleza en su condición telúrica y genésica es el rasgo que identifica este Edén patagónico. Lugar primordial, donde paradójicamente, la imagen de Dios como entidad iniciadora de mundo está ausente, dado que así se desprende de los primeros fragmentos del corpus poemático, a diferencia de lo que acontece con su intertexto bíblico: "Si Dios no visitó sus patagonias,/ si allí en el último Edén, el de los dolores,/ nadie apareció sentado en el cielo" (XIV). Y también en el fragmento XVI: "y como este hombre no tenía cielo/ buscó la enmarañada rosa verde/ del territorio secreto:/". Se alude asimismo a la ausencia de Dios en este territorio desolado cuando el hablante refiere la imposibilidad de que la primera mujer sea creada a partir del sujeto adánico: "Ya no podía nacer de su cuerpo/ porque en su cielo no mandaba nadie./ Él era su propio cielo verde" (XVII). Sin embargo, es preciso advertir que la alusión a la falta de Dios en este ámbito del extremo austral chileno no es nueva al interior del universo nerudiano. La ausencia de la idea cristiana de Dios concebida como institucionalidad religiosa que rige a una comunidad determinada está presente también, por ejemplo, en Canto general, sección "Gran océano", cuando el hablante describe a los habitantes originarios de este rincón apartado: "Sin más dioses que el cuero de las focas podridas/ honor del mar, yámanas azotados/ por el látigo antártico, alacalufes/ untados con aceites y detritus:/ entre los muros de cristal y abismo" (OC, I, 777). Ciertamente y como es sabido, la institucionalidad cristiana llega a América a partir del proceso de colonización. No obstante, en este territorio lejano y de difícil acceso por sus características geográficas y climáticas rigurosas, el proceso evangelizador no llegó a consolidarse como lo hizo en la mayor parte del territorio americano y chileno. El hablante nerudiano parece tener presente tales circunstancias, es decir, la condición marginal de este espacio con respecto a la institucionalidad religiosa que el proceso colonizador trajo consigo. Desde esta perspectiva, esta región funciona míticamente como ámbito primigenio, porque se aparta o se excluye en virtud de su propia naturaleza del proceso histórico que se origina en la cosmovisión cristiana de fundación de mundo que comenzó a hacerse efectiva con la llegada de los 
españoles a América. Lugar edénico, entonces, apto para reiniciar la historia de la humanidad, para fundar un "Nuevo Mundo", ahora sí, que nada tendría que ver con aquella historia de violencia y muerte que el protagonista de $L a$ espada encendida ha dejado atrás: "Yo, Rhodo, destruí el camino/para no regresar. Busqué y amé/ la paz deshabitada" (XVIII), historia que en su origen el sujeto poético adscribe a la tradición judeocristiana: "Caín y Abel cayeron muchas veces/ (asesinados un millón de veces)/ (un millón de quijadas/ y quebrantos)" (XV). ¿Pero qué implica fundar un nuevo mundo en un territorio salvaje, vale decir, sin historia y como consecuencia, sin Dios? O más bien sin aquella imagen institucionalizada de Dios traída por los conquistadores. Para intentar una respuesta vale la pena considerar lo que el estudioso de las religiones Mircea Eliade propone en Lo sagrado y lo profano, acerca de la noción de espacio sagrado ${ }^{5}$ pensado en torno al proceso de "descubrimiento y conquista de América".

Mircea Eliade señala que para el hombre religioso el espacio no es homogéneo, lo que se traduce en la oposición entre un espacio con significado y estructura que corresponde al espacio sagrado, y un ámbito informe, vacío de significado que corresponde al espacio no consagrado. Un lugar se hace sagrado mediante una ruptura que se opera en el espacio homogéneo, esta ruptura equivale a una manifestación hierofánica que revela un punto fijo, un centro de orientación que permite el establecimiento y la vida organizada. Ahora bien, Eliade recurre al término hierofanía ${ }^{6}$, atendiendo a su carga etimológica, para denominar aquella manifestación de lo sagrado que ocurre como un acto absolutamente distinto a cualquier hecho de la vida común:

Se trata siempre del mismo acto misterioso: la manifestación de algo "completamente diferente", de una realidad que no pertenece a nuestro mundo, en objetos que forman parte integrante de nuestro mundo "natural", "profano" (19).

5 En el capítulo I de este libro, el autor desarrolla el tema de la sacralización del espacio y su compartimentación entre cosmos y caos que se origina como consecuencia de esta sacralización.

6 Hierofanía es un neologismo que reúne dos raíces griegas: hier, sacro y fain, manifestar(se), mostrar(se). Escapa a este análisis abordar y desarrollar la noción de hierofanía más allá de su carácter ritual implicado en los actos de consagración territorial como actos que autorizan la toma de posesión de un espacio determinado. 
Respecto a las implicancias de esta manifestación de lo sagrado que sobredetermina un espacio, este autor señala lo siguiente:

Desde el momento en que lo sagrado se manifiesta en una hierofanía cualquiera no sólo se da una ruptura en la homogeneidad del espacio, sino también la revelación de una realidad absoluta, que se opone a la no-realidad de la inmensa extensión circundante (26).

En el contexto religioso del proceso de "descubrimiento y conquista de América", el acto hierofánico que consagra un territorio se traduce en la ceremonia cosmogónica ${ }^{7}$ judeocristiana que repite la creación del universo reiterando la obra ejemplar de Dios. Es importante tener presente en este mismo contexto, que al tomar posesión de un territorio mediante el ritual cosmogónico, el lugar se revela ontológicamente, se re-crea, fundándose un mundo. En este sentido, el espacio patagónico como lugar prácticamente inaccesible queda situado al margen de esta ritualidad, pudiendo visualizársele como esa "no realidad de la inmensa extensión circundante", que es señalada por Eliade, en oposición a aquella "realidad absoluta" que representa el territorio habitado y organizado mediante el acto hierofánico. Este autor ejemplifica esta modalidad ritual de ocupación de un territorio, ilustrando con lo que aconteció durante el período de lo que se llamó "La conquista de América":

Los "conquistadores" españoles y portugueses tomaban posesión en nombre de Jesucristo, de los territorios que habían descubierto y conquistado. La erección de la Cruz consagraba la comarca, equivalía en cierto modo, a un "nuevo nacimiento": por Cristo, "las cosas viejas han pasado; he aquí que todas las cosas se han hecho nuevas" (2 Corintios 5, 17). El país recién descubierto quedaba "renovado", "recreado" por la Cruz (34).

Cabe hacer notar que en la trayectoria del sujeto nerudiano, especialmente para el sujeto poético de Canto general, el símbolo de la cruz posee un carácter

7 La RAE define cosmogonía en su primera acepción como relato mítico relativo a los orígenes del mundo. El Diccionario de uso del español, de María Moliner, indica que su etimología proviene del griego, kosmos: mundo, orden, arreglo y de gignomai: producirse. El término caos como opuesto a cosmos es definido por la RAE como estado amorfo e indefinido que se supone anterior a la ordenación del cosmos. Su etimología tiene también origen griego y significa abertura, abismo. 
negativo asociado a la codicia y la crueldad del proceso expedicionario, así por ejemplo, sección "Los conquistadores", "Cita de cuervos":

El Perú oscuro, sumergido

estaba señalado y las cruces,

pequeñas, negras, negras cruces

al Sur salieron navegando:

cruces para las agonías,

cruces peludas y filudas,

cruces con gancho de reptil,

cruces salpicadas de pústulas,

cruces como piernas de araña,

sombrías cruces cazadoras (OC I, 460-461).

Siguiendo lo propuesto por Eliade, el territorio del extremo austral chileno, representado como ámbito edénico en la fábula, correspondería a un lugar inexistente, amorfo e irreal, en oposición a los demás espacios consagrados. "Cosmos" y "Caos", de acuerdo a lo que describe este autor, dan cuenta de este modo de visualizar el mundo, escindido en dos espacios antagónicos:

Lo que caracteriza a las sociedades tradicionales es la oposición que tácitamente establecen entre su territorio habitado y el espacio desconocido e indeterminado que les circunda: el primero es el "Mundo" (con mayor precisión: "nuestro mundo"), el Cosmos; el resto ya no es un Cosmos, sino una especie de "otro mundo", un espacio extraño, caótico, poblado de larvas, de demonios, de "extranjeros". [...] Un territorio desconocido, extranjero, sin ocupar (lo que quiere decir con frecuencia: sin ocupar por "los nuestros"), continúa participando de la modalidad fluida y larvaria del "Caos". Al ocuparlo y, sobre todo, al instalarse en él, el hombre lo transforma simbólicamente en Cosmos por una repetición ritual de la cosmogonía (Eliade 32-33).

Sobrepasa los objetivos de esta lectura considerar las múltiples implicaciones que pueden derivarse de esta separación espacial del mundo en "Cosmos" y "Caos" para la narración de la historia del "descubrimiento y conquista de América" relativa al proceso de ocupación del territorio. No obstante, es posible afirmar que el paisaje americano del centro al sur del continente albergará en la mirada distante del europeo primero, y luego en la del hombre "civilizado" en general, esa carga de lo remoto, de lo desconocido y de lo extraño que se despliega a partir de la idea de caos. Calificativos tales como 
"desolado", "indómito", "agreste" repiten y amplifican esta idea aplicada al paisaje patagónico, sin embargo, en el relato que va conformando este espacio edénico peculiar, representado en el mundo de La espada encendida, subyacen también otros calificativos como "virginal", "prístino" e "intocado", que aluden a un espacio primordial: "Es la selva del árbol de la vida. El racimo/ de cada planta, el peso de la fruta salvaje,/ nos nutrió de repente, y estuvimos desnudos/ hasta morir de amor y de dolor" (XII).

Será, sin embargo, la idea de Terra incógnita la que prevalecerá en el imaginario colectivo universal cuando se haga referencia a la Patagonia, imagen que también está muy presente en el enunciador nerudiano. Así, por ejemplo, cuando el sujeto poético de la sección "Los conquistadores" de Canto general describe a Hernando de Magallanes y su trágica navegación por los tempestuosos mares del extremo sur chileno. Resulta imposible no pensar en ese "otro mundo" de pesadilla que Eliade describe como "Caos" en versos como el que sigue: "La dura tierra extraña guarda sus calaveras/ que suenan en el pánico austral como cornetas" (OC, $I, 474)$ y también en los versos siguientes: "sólo queda el dominio quemado y sin cadáveres,/ la incesante intemperie apenas rota/ por un negro fragmento/ de fuego fallecido" $(O C, I, 474)$. El ser humano parece atrapado e integrado en la oscura dinámica de una naturaleza implacable que pareciera ensañarse con aquel hombre que sueña con explorar (y explotar) esos territorios difíciles. En el mundo de La espada encendida el paisaje patagónico muchas veces se representa de manera semejante:

el espacio que abría la boca una vez más, tragándolos, llevándolos entre espina y espina como en una oceánica guerra sin regimientos, sin más tambor que el trueno, y adelante y atrás, arriba, abajo, aquel reino erizado que continuaba hacia el Polo $[\ldots]$ (XXIII).

En esta región compleja, donde la naturaleza reina con majestad absoluta, la ritualidad religiosa imbricada en el acto de toma de posesión de un territorio resulta ineficaz. El hablante de Canto general ve en estas ceremonias solo artimañas para someter a los pueblos descubiertos. La ferocidad de este 
espacio inhóspito pareciera no aceptar la intromisión del hombre y sus símbolos hegemónicos. En este contexto, la figura del expedicionario que se aventuró en esta zona parece insignificante frente a la naturaleza avasalladora, ironizándose el aura de divinidad que tuvo la figura del conquistador en otros territorios ubicados más al norte del continente americano: "Cuál es el dios que pasa? Mirad su barba llena de/gusanos/y sus calzones en que la espesa atmósfera/ se pega y muerde como un perro náufrago" $(O C, I$, 475) es lo que pregunta el hablante apelando a Magallanes en el fragmento "Recuerdo al viejo descubridor". De igual modo, para este mismo sujeto poético, la religión cristiana en su aspecto ritual forma parte también de los artificios que arrastra el "descubridor" en su afán de dominio, ritualidad que se desvanece o transmuta en misterio oceánico cuando Magallanes naufraga y muere: "y no tiene de cruz tu pecho sino un grito/ del mar, un grito blanco, de luz marina, / y de tenaza, de tumbo en tumbo, de aguijón demolido" (OC, $I, 475)$. Y ya casi al final del fragmento "Todos han muerto", el enunciador parece articular en una misma derrota la codicia y el bagaje ritual que el expedicionario trae consigo: "Al fin, ya tenéis vuestro paraíso perdido,/ al fin, tenéis vuestra guarnición maldiciente,/al fin, vuestros fantasmas atravesados del aire/ besan sobre la arena la huella de la foca" $(O C, I, 475)^{8}$.

A la luz de lo planteado por Mircea Eliade, respecto a la consagración del espacio y a la separación del mismo entre "Caos" y "Cosmos", la región patagónica chilena, representada míticamente en la fábula, puede interpretarse como un espacio no consagrado. Territorio desconocido y sin historia, lugar del caos, puesto que no pudo ser eficazmente re-creado mediante la repetición del rito cosmogónico de la erección de la Cruz. Los rasgos peculiares de la zona patagónica han impedido su ocupación según el modo convencional de asentamiento en un territorio. En medio de este paisaje grandioso, pero abrupto, sumado al rigor de su clima, el hombre y su afán de dominio no producen efectos, la toma de posesión a través del ritual carece de sentido.

8 El último verso -"besan sobre la arena la huella de la foca"- tal vez podría interpretarse en relación con otro verso citado anteriormente en esta lectura: "Sin más dioses que el cuero de las focas podridas" (OC I, 777), relativo a la idea de la ausencia de Dios en este espacio patagónico. Cabe considerar que el gesto de besar la tierra constituye el acto simbólico de adoración al Creador al interior de la cosmovisión cristiana, por lo tanto, ambas versos implican imágenes fuertes asociadas no al repudio de la experiencia religiosa en sí misma, sino en cuanto ésta estuvo adscrita al devastador proceso expedicionario. 
De este modo, lo imposible de "fundar" implica la carencia de Dios, lo desconocido equivale entonces a lo "salvaje".

Espacio apto para reiniciar la historia de la humanidad, el "Nuevo Mundo", ahora sí, pero cuya consagración ya no descansaría en la ritualidad cosmogónica cristiana, de acuerdo a la cosmovisión planteada en la fábula, sino en la propia naturaleza telúrica y genésica de este Edén austral, cuya máxima expresión estaría dada por el vínculo erótico de la nueva pareja edénica.

\section{BIBLIOGRAFÍA}

Concha, Jaime. Neruda (1904-1936). Santiago: Universitaria, 1972.

Eliade, Mircea. Lo sagrado y lo profano. Barcelona: Labor, 1967.

Martinic, Mateo. Archipiélago patagónico: La última frontera. Punta Arenas: Universidad de Magallanes, 2004.

Neruda, Pablo. Obras completas. Cinco tomos. Ed. Hernán Loyola. Barcelona: Galaxia Gutenberg/Círculo de Lectores, 1999.

Sautereau, Jacques. "Última Patagonia”. http://centreterre.fr/ultima2000/pdf/Ultima_es.pdf Sicard, Alain. El pensamiento poético de Pablo Neruda. Madrid: Gredos, 1981. 